\title{
Responsible Research and Innovation: an opportunity to develop creative skills at Higher Education
}

\author{
Rodriguez, Gemma; Saladie, Núria; Revuelta, Gema; Vizuete, Clara; Llorente, \\ Carolina; Carrió, Mar \\ Health Sciences Education Research Group, Department of Experimental and Health \\ Sciences, Univeritat Pompeu Fabra, Spain.
}

\begin{abstract}
During the last decades, research and innovation have experienced a revolution that has lead to new challenge, and creativity has been identified as a main skill for professional success. In this context, not only concerns about involving society in research and innovation processes have been increasing but also to make this process responsible. Responsible Research and Innovation (RRI) has been defined as the approach for making research and innovation a collaborative, intergenerational and democratic process. The HEIRRI project aims to integrate RRI at all stages of education with the creation of different programs in Higher Eduaction. The aim of this study is assess how creativity has been developed in an RRI framework in the HEIRRI Summer School programme troughout an Inquiry-Based Learning (IBL) approach. On the basis of the results, this paper highlights that the IBL approach, but also the RRI framework foster creativity development in a research proposal design but also that have an impact on how researchers' perceive their profession. This paper concludes that integral elements of this pedagogical approach and RRI, such as discussion, multidisciplinarity and including different voices and perspectives are main ingredients to promote creativity in research and innovation processes and have a transformative potential.
\end{abstract}

Keywords: Responsible Research and Innovation, Creativity, Inquiry-Based Learning, Multidisciplinarity, HEIRRI project. 


\section{Introduction}

During the late 20th and 21st centuries, research and innovation have experienced a revolution that has had an impact on human development. New challenges have emerged, and to deal with them some skills have become an urgent need. Creativity has been identified as one of the main and needed skills for professional success and adaptability to constant changing environment.

Creativity is an integral property of research and innovation processes. Researchers are challenged create knowledge as new experts: new questions, deductive and inductive reasoning and combination of unrelated knowledge are properties of this process closely linked to creativity (Barrow, 2010). Although creativity has been always identified as the ability of individuals to generate new ideas, in fact, it is considered as the interaction between aptitude, process and environment where a group of individuals produce something new and useful in a social context (Plucker et al., 2004). Creativity is defined as a social and collaborative phenomenon that requires interaction and discussion (Hadzigeorgiou et al., 2012). Creative thinking a social phenomenon involving interactions among people; it's a property of social groups (Sawyer, 2006).

This global revolution has lead, not only to the crucial development of creativity in research, but also to foster research and innovation processes aligned to the societal need and values, to involve society in the process of decision taking about how research has to be developed. After the Second World War, countries stopped needing military equipment and research started thinking about what society really required to produce reliable knowledge. To that end, not only research had to speak to society, this communication was compelled to be bidirectional (Gibbons, 1999). In recent years, not only concerns about involving society in research and innovation processes have been increasing, but also to make these processes responsible. This movement of responsibility, called Responsible Research and Innovation (RRI), has been defined by Stilgoe et al. (2013) as "(...) taking care of the future through collective stewardship of science and innovation in the present". Approaches to responsible innovation extended the governance discussion to encompass questions of uncertainity, purposes, motivations, social and political constitutions and directions of innovation. In this framework four dimensions of responsibility were proposed: anticipation, reflexivity, inclusion and responsiveness (Stilgoe et al., 2013).

In this context, research has lead to new models for collaborative research at large scale (Esparza \& Yamada, 2007). It has become a driver for innovation and academic research has participated in large and collaborative big science projects, characterized by multidisciplinary teams (Vermeulen, 2010). This kind of projects collect members of different domains to work collaboratively to make discoveries that impact knowledge, future education and healthcare (Oandasan \& Reeves, 2009). Big Science has become an 
important way to harness researchers' creativity and enhance innovation through collaboration, multidisciplinarity and group thinking, but also an essential scenario of promoting responsible research and innovation (Esparza \& Yamada, 2007).

The Higher Education Institutions \& Responsible Research and Innovation (HEIRRI) is a Horizon 2020 project that aims to integrate the concept of RRI at all stages of education of scientists and engineers, as well as other fields working on or affected by R\&I.

Inquiry-based learning (IBL) is one of the pedagogical approaches used in the HEIRRI project to teach RRI, as well as fostering collaborative creativity. The IBL approach models the general process of investigation that scientists use to answer questions in the real world. It allows students to learn different skills, to apply knowledge and find a solution to a complex problem (Savery, 2006). It simulates real investigations to make students learn while practicing important creative skills such as problem-solving, collaboration, autonomy, considering alternative solutions, investigating different scenarios and exploring new questions (Hämäläinen \& Vähäsantanen, 2011; Tan et al., 2009). To foster creativity, many techniques can be developed, such as stimulatory techniques (brainstorming or mind mapping), problem-solving techniques or expert facilitation techniques (Adams et al., 2009). Furthermore, working with multidisciplinary groups can also enhance creative ideas due to the existence of different points of view and the possibility to share a large variability of experiences (Adams et al., 2009).

The HEIRRI project has developed ten different programs to introduce RRI in Higher Education thorugh active learning methodologies. One of the programs, the Summer School, which used the IBL approach, congregated participants from different fields who had to develop a research proposal incorporating the RRI perspective. In this paper, we analyze how the participants of the HEIRRI Summer School have developed creativity in an RRI framework throughout the IBL approach and its transformative potential.

\section{Materials and Methods}

\subsection{Participants}

This study was run at Pompeu Fabra University (UPF) during the HEIRRI Summer School on September 2017. There were 15 participants with different research experiences $(\mathrm{PhD}$ students, faculty and senior research staff, research managers, administration and services staff, etc.) enrolled in this program. The participants came from different disciplines such as experimental sciences, political sciences, humanities and translation and interpretation, for example. In this course, 13 participants were female and 2 participants were male. Despite the sample isn't gender balanced, no gender statistical differences have been found. 


\title{
2.2. Study design and setting
}

The HEIRRI project has developed different training programs to integrate the concept of RRI at different stages of the Higher Education Institutions. One of the programs, implemented in Pompeu Fabra University (UPF), has been carried out as a Summer School to integrate in the everyday practice and foster reflection on RRI for different staff of the university. The Inquiry-Based Learning approach was used to integrate RRI in a practical way to propose a solution for a complex and transversal scenario: Ageing. The Summer School was performed during four days, in which 5 sessions of 4 hours took place. Different activities were integrated in the framework of the IBL approach.

Table 1. Summer School course activities overview.

\section{Activities}

\section{Description of the activities}

\begin{abstract}
Day 1 Brainstorming The participants had to design a multidisciplinary research proposal from a transdisciplinar scenario, ageing, and had to incorporate the basic RRI dimensions.
\end{abstract}

Day 2 Jigsaw activity The participants discussed the RRI key issues in small groups with an expert on the field. They had to apply the discussed issues to the research project proposal.

Walkshop The participants shared their reflections on RRI and on the research projects in a distended context walking around the city.

Day 3 Museum activity The participants performed a science café to involve the affected and involved stakeholders' point of view on the research proposal.

Day 4 RRI-project The participants presented their proposals and discussed presentations how RRI can be included to a research project.

\subsection{Data collection and analysis}

In this study we examined the development of creative skills throughout the implementation of the IBL approach at the HEIRRI Summer School within an RRI framework. The study has the ethical approval from the UPF and the informed consent of all the participants.

The empirical data was collected through a questionnaire solicited at the end-of-course, that were provided to the research team in an anonymous form. The analysis included all the 
responses related to the course. The questionnaire was analyzed through qualitative and quantitative methodologies.

\section{Results}

To analyse how creativity has been developed in an RRI framework throughout the IBL approach and if this pedagogical approach has a transformative quality. The quantitative and qualitative results of the questionnaire have been analysed.

Table 2. Quantitative results of the questionnaire from 1 (strongly disagree) to 7 (strongly agree) $(\mathbf{n}=10)$.

\begin{tabular}{|l|l|l|l|}
\hline Questions & Mean & SD & Mode \\
\hline $\begin{array}{l}\text { The inquiry based methodology proposed in the Summer School } \\
\text { fosters the development of creativity in a research proposal } \\
\text { design. }\end{array}$ & 6.40 & 0.84 & 7 \\
\hline The Ageing context may interest different disciplines. & 6.70 & 0.48 & 7 \\
\hline $\begin{array}{l}\text { The openness of the Ageing context facilitates the creation of } \\
\text { ideas from different disciplines. }\end{array}$ & 6.40 & 0.97 & 7 \\
\hline The Ageing context can be related to your own research line. & 4.50 & 2.07 & 6 \\
\hline The Ageing context can be related to your own experiences. & 5.40 & 1.95 & 7 \\
\hline $\begin{array}{l}\text { Collaboration between researchers of different disciplines fosters } \\
\text { the generation of the creative ideas. }\end{array}$ & 6.60 & 1.26 & 7 \\
\hline $\begin{array}{l}\text { Including the RRI perspective in the research project proposal } \\
\text { design has favored the development of a more creative project } \\
\text { design. }\end{array}$ & 6.22 & 0.97 & 7 \\
\hline $\begin{array}{l}\text { Including the RRI perspective in the research project proposal } \\
\text { design has limited the development of a more creative project } \\
\text { design. }\end{array}$ & 1.89 & 1.36 & 1 \\
\hline $\begin{array}{l}\text { During the course, participants can verbalize their beliefs about } \\
\text { science and society relationship. }\end{array}$ & 6,40 & 1.07 & 7 \\
\hline $\begin{array}{l}\text { During the course, participants can discuss different points of } \\
\text { view/perspectives }\end{array}$ & 6.30 & 1.06 & 7 \\
\hline $\begin{array}{l}\text { During the course, a constructive dialogue is generated giving } \\
\text { way to new conceptions. }\end{array}$ & 5.90 & 1.20 & 7 \\
\hline $\begin{array}{l}\text { During the course, my point of view on the science and society } \\
\text { relationship has changed. }\end{array}$ & 5.10 & 1.73 & 6 \\
\hline
\end{tabular}


Table 3. Qualitative results of the questionnaire analysed thorugh categorisation system $(n=10)$.

\begin{tabular}{|c|c|c|c|}
\hline Category & $\begin{array}{c}\text { Sub- } \\
\text { category }\end{array}$ & $\begin{array}{c}\text { Further } \\
\text { subcategory }\end{array}$ & Findings \\
\hline \multirow[t]{3}{*}{ Creativity } & $\begin{array}{l}\text { IBL } \\
\text { pedagogical } \\
\text { approach }\end{array}$ & Scenario & $\begin{array}{l}\text { The participants of the summer school state } \\
\text { that a global, broad, relevant, shift paradigm } \\
\text { scenario that implies emotionally } \\
\text { participants can promote creativity } \\
\text { development in a research proposal. }\end{array}$ \\
\hline & & $\begin{array}{l}\text { Multi- } \\
\text { disciplinarity }\end{array}$ & $\begin{array}{l}\text { Discussion between participants of different } \\
\text { fields was very productive. Different } \\
\text { perspectives, as well as emotional and } \\
\text { personal experiences, makes them think } \\
\text { about some points they never thought } \\
\text { before, but also to think in a different way } \\
\text { and enrich their proposal. }\end{array}$ \\
\hline & $\begin{array}{l}\text { RRI } \\
\text { theoretical } \\
\text { framework }\end{array}$ & $\begin{array}{l}\text { RRI } \\
\text { integration }\end{array}$ & $\begin{array}{l}\text { Taking into account the RRI perspectives, } \\
\text { makes develop more ideas, incorporate new } \\
\text { points of view, and anticipate consequences } \\
\text { of the developed ideas. }\end{array}$ \\
\hline $\begin{array}{l}\text { Transfor- } \\
\text { mative } \\
\text { potential }\end{array}$ & & & $\begin{array}{l}\text { The RRI perspective, multidisciplinarity, } \\
\text { including different points of view and } \\
\text { rethinking ideas had an impact on how } \\
\text { researchers perceive their research. }\end{array}$ \\
\hline Limitation & & & $\begin{array}{l}\text { Some activities were more useful than } \\
\text { others. However most people regret not } \\
\text { having enough time. }\end{array}$ \\
\hline
\end{tabular}

\section{Discussion}

The findings of this study suggest that the IBL approach had a positive impact on creativity development. As the results show, this pedagogical approach fosters the development of creativity in a research proposal design. Presenting an open and broad scenario that include different disciplines and perspectives can facilitate the creation of new and multidisciplinary ideas. A context which can engage emotionally people can contribute also to this issue. Furthermore, interprofessional groups with people of different fileds is seen as a fact of creativity development. Different perspectives and points of view makes 
participants' think in a different way and incorporate more original and innovative ideas in a research proposal, but also explore different options, solutions or arguments in a bigger framework or complex situation. Some techniques used during this course also facilitate this process, the science café and the post-it brainstorming are good examples of that.The $100 \%$ of the participants considered that the science cafe fostered the creativity of their research proposal, and the 55,5\% that the post-it brainstorming increased too. In fact, creativity is a complex and multifaceted topic, and some studies have identified different factors that contribute to its promotion: improvisation, collaboration, problem-solving, openness and flexibility are essential to creative thinking development (Hämäläinen and Vähäsantanen, 2011). Furthermore, creativity is defined as a property of groups, is a social phenomenon involving interactions among people (Sawyer, 2006). When a working environement brings together individuals from different disciplines and domains and who have different perspectives, the creative potential is enhanced due to different ideas and unexpected connections (Adams et al., 2009). The participants considered with a mean of 6,6 out of 7 that collaboration between researchers of different disciplines fosters the generation of the creative ideas.Some teccniques are positive to increase this phenomenon in idea generation and evaluation steps; stimulatory techniques that promote alternative thinking or interaction enhace creative thinking (Adams et al., 2009).

Furthermore, the results also show that not just the pedagogical approach fosters creativity but also the theoretical framework in within the Summer School was developed. Including the RRI perspective into research proposal design maked participants think in a deeper way and develop more their ideas, inspect other points of view, analyse information in a different perspective, include different voices and take into account perceptions that they hadn't think before. RRI seeks to bring issues related to research and innovation into the open, to anticipate their consequences and to involve society in discussing how science and technology can help create the kind of world and society we want for generations to come (Smyranio et al., 2017). The four dimensions of responsibility provides a framework for raising, discussing and responding a set of questions that arise from public dialogues on science and public concerns (Stilgoe et al., 2103). This discussion between different stakeholders with different backgrounds but also different perspectives of how research and innovation has to be performed is a theoretical framework that can contribute to creative thinking enhancement, if there is enough time to discuss and reflect.

Finally, this course has became an open and safe environment where the participants could verbilise their beliefs about science and society, disscuss different perspectives and generate a constructive dialogue about all the trated issues, but also has been useful to change researchers preconceptions about science and society and had an impact on how researchers perceive their profession and research field. 


\section{Conclusions}

Integral elements of the Inquiry-Based Learning approach, but also from th RRI movement, such as discussion on open and flexible contexts, multidisciplinarity and including different voices and perspectives are main ingredients to promote creativity in research and innovation processes. Furthermore, this experience had a positive impact on how the professionals perceive their profession and its influence on society.

\section{References}

Adams, D., Beniston, L., \& Childs, P. (2009). Promoting creativity and innovation in biotechnology. Trends in Biotechnology, 27(8), 445-447. doi: 10.1016/j.tibtech.2009.05.001

Barrow, L. (2010). Encouraging Creativity with Scientific Inquiry. Creative Education, 1(01), 1-6. doi: 10.4236/ce.2010.11001

Esparza, J., \& Yamada, T. (2007). The discovery value of "Big Science". The Journal of Experimental Medicine, 204(4), 701-707. doi: 10.1084/jem.20070073 PMDI:1740271

Gibbons, G. (1999). Science's new social contract with society. Nature, 402. SUPP.

Hadzigeorgiou, Y., Fokialis, P., \& Kabouropoulou, M. (2012). Thinking about Creativity in Science Education. Creative Education, 3(5), 603-611. doi: 10.4236/ce.2012.35089

Hämäläinen, R., \& Vähäsantanen, V. (2011). Theoretical and pedagogical perspectives on orchestrating creativity and collaborative learning. Educational Research Review, 6(3), 169-184. doi: 10.1016/j.edurev.2011.08.001

Oandasan, I., \& Reeves, S. (2009). Key elements for interprofessional education. Part 1: The learner, the educator and the learning context. Journal of Interprofessional Care, 19(1), 21-38. PMID: 16096143

Plucker, J. A., Beghetto, R. A., \& Dow, G. T. (2004). Why isn't creativity more important to educational psychologist? Potential, pitfalls, and future directions in creativity research. Educational Psychologist, 39(2), 83-97. doi: 10.1207/s15326985ep3902_1

Savery, J. R. (2006). Overview of Problem-Based Learning: Definitions and Distinctions. Interdisciplinary Journal of Problem-Based Learning, 1(1), 9-20. doi: 10.7771/15415015.1002

Sawyer, R. K., (2006). Explaining creativity: The science of human innovation. New York: Oxford University Press.

Smyranio, Z., Georgakopoulou, E., Sotiriou, M., Sotiriou, S. (2017). The Learning Science thorugh Theatre initiative in the context of Responsible Research and Innovation. Journal of Systemics, Cybernetics and Informatics, 15(5), 14-22.

Stilgoe, J., Owen, R., \& Macnaghten, P. (2013). Developing a framework for responsible innovation. Research Policy, 42, 1568-1580.

Vermeulen, N., Parker, J. N., \& Penders, B. (2010). Big, small or mezzo. EMBO Reports, 11(6), 420-423. doi: 10.1038/embor.2010.67 PMID: 20467436 